\title{
Monotone Hybrid Projection Algorithms for an Infinitely Countable Family of Lipschitz Generalized Asymptotically Quasi-Nonexpansive Mappings
}

\author{
Watcharaporn Cholamjiak $^{1,2}$ and Suthep Suantai ${ }^{1,2}$ \\ ${ }^{1}$ Department of Mathematics, Faculty of Science, Chiang Mai University, Chiang Mai 50200, Thailand \\ ${ }^{2}$ PERDO National Centre of Excellence in Mathematics, Faculty of Science, Mahidol University, \\ Bangkok 10400, Thailand
}

Correspondence should be addressed to Suthep Suantai, scmti005@chiangmai.ac.th

Received 24 August 2009; Revised 5 November 2009; Accepted 27 November 2009

Recommended by Simeon Reich

We prove a weak convergence theorem of the modified Mann iteration process for a uniformly Lipschitzian and generalized asymptotically quasi-nonexpansive mapping in a uniformly convex Banach space. We also introduce two kinds of new monotone hybrid methods and obtain strong convergence theorems for an infinitely countable family of uniformly Lipschitzian and generalized asymptotically quasi-nonexpansive mappings in a Hilbert space. The results improve and extend the corresponding ones announced by Kim and Xu (2006) and Nakajo and Takahashi (2003).

Copyright (c) 2009 W. Cholamjiak and S. Suantai. This is an open access article distributed under the Creative Commons Attribution License, which permits unrestricted use, distribution, and reproduction in any medium, provided the original work is properly cited.

\section{Introduction}

Let $C$ be a nonempty, closed, and convex subset of a real Banach space $E$. We denote by $F(T)$ the set of fixed points of $T$, that is, $F(T)=\{x \in C: x=T x\}$. Then $T$ is said to be

(i) nonexpansive if $\|T x-T y\| \leq\|x-y\|$ for all $x, y \in C$;

(ii) asymptotically nonexpansive if there exists a sequence $k_{n} \geq 1, \lim _{n \rightarrow \infty} k_{n}=1$ and

$$
\left\|T^{n} x-T^{n} y\right\| \leq k_{n}\|x-y\|
$$

for all $x, y \in C$ and $n \geq 1$; 
(iii) asymptotically quasi-nonexpansive if there exists a sequence $k_{n} \geq 1, \lim _{n \rightarrow \infty} k_{n}=1$ and

$$
\left\|T^{n} x-p\right\| \leq k_{n}\|x-p\|
$$

for all $x \in C, p \in F(T)$ and $n \geq 1$;

(iv) generalized asymptotically nonexpansive [1] if there exist nonnegative real sequences $\left\{k_{n}\right\}$ and $\left\{c_{n}\right\}$ with $k_{n} \geq 1, \lim _{n \rightarrow \infty} k_{n}=1$ and $\lim _{n \rightarrow \infty} c_{n}=0$ such that

$$
\left\|T^{n} x-T^{n} y\right\| \leq k_{n}\|x-y\|+c_{n}
$$

for all $x, y \in C$ and $n \geq 1 ;$

(v) generalized asymptotically quasi-nonexpansive [1] if there exist nonnegative real sequences $\left\{k_{n}\right\}$ and $\left\{c_{n}\right\}$ with $k_{n} \geq 1, \lim _{n \rightarrow \infty} k_{n}=1$ and $\lim _{n \rightarrow \infty} c_{n}=0$ such that

$$
\left\|T^{n} x-p\right\| \leq k_{n}\|x-p\|+c_{n}
$$

for all $x \in C, p \in F(T)$ and $n \geq 1$;

(vi) asymptotically nonexpansive in the weak sense [2] if

$$
\limsup _{n \rightarrow \infty} \sup _{y \in C}\left(\left\|T^{n} x-T^{n} y\right\|-\|x-y\|\right) \leq 0
$$

for all $x \in C$.

(vii) asymptotically nonexpansive in the intermediate sense [3] if

$$
\limsup _{n \rightarrow \infty} \sup _{x, y \in C}\left(\left\|T^{n} x-T^{n} y\right\|-\|x-y\|\right) \leq 0
$$

(viii) uniformly L-Lipschitzian if there exists a constant $L>0$ such that

$$
\left\|T^{n} x-T^{n} y\right\| \leq L\|x-y\|
$$

for all $x, y \in C$ and $n \geq 1$.

It is clear that a generalized asymptotically quasi-nonexpansive mapping is to unify various classes of mappings associated with the class of generalized asymptotically nonexpansive mapping, asymptotically nonexpansive mappings, and nonexpansive mappings. However, the converse of each of above statement may be not true. The example shows that a generalized asymptotically quasi-nonexpansive mapping is not an asymptotically quasinonexpansive mapping; see [1]. Note that if $T$ is asymptotically nonexpansive in the weak sense, we have that

$$
\left\|T^{n} x-T^{n} y\right\| \leq k_{n}\|x-y\|+c_{n}
$$


for all $x, y \in C$, where $c_{n}=\max \left\{0, \sup _{x, y \in C}\left(\left\|T^{n} x-T^{n} y\right\|-\|x-y\|\right)\right\}$ so that $\lim _{n \rightarrow \infty} c_{n}=0$. Hence, $T$ is a generalized asymptotically nonexpansive mapping.

The mapping $T: C \rightarrow C$ is said to be demiclosed at 0 if for each sequence $\left\{x_{n}\right\}$ in $C$ converging weakly to $x$ and $\left\{T x_{n}\right\}$ converging strongly to 0 , we have $T x=0$.

A Banach space $E$ is said to satisfy Opial's property, see [4], if for each $x \in E$ and each sequence $\left\{x_{n}\right\}$ weakly convergent to $x$, the following condition holds for all $x \neq y$ :

$$
\liminf _{n \rightarrow \infty}\left\|x_{n}-x\right\|<\liminf _{n \rightarrow \infty}\left\|x_{n}-y\right\|
$$

Let $\tau$ be a Hausdorff linear topology and let $E$ satisfy the uniform $\tau$-Opial property. In 1993, Bruck, Kuczumow, and Reich proved that $\left\{T^{n} x\right\}$ is $\tau$-convergent if and only if $\left\{T^{n} x\right\}$ is $\tau$-asymptotically regular, that is,

$$
T^{n+1} x-T^{n} x \stackrel{\tau}{\rightarrow} 0
$$

Moreover, they also proved that the $\tau$-limit of $\left\{T^{n} x\right\}$ is a fixed point of $T$.

In 1953, Mann [5] introduced the following iterative procedure to approximate a fixed point of a nonexpansive mapping $T$ in a Hilbert space $H$ :

$$
x_{n+1}=\alpha_{n} x_{n}+\left(1-\alpha_{n}\right) T x_{n}, \quad \forall n \in \mathbb{N},
$$

where the initial point $x_{0}$ is taken in $C$ arbitrarily and $\left\{\alpha_{n}\right\}$ is a sequence in $[0,1]$.

However, we note that Mann's iteration process (1.11) has only weak convergence, in general; for instance, see [6-8].

In 2003, Nakajo and Takahashi [9] proposed the following modification of the Mann iteration for a single nonexpansive mapping $T$ in a Hilbert space. They proved the following theorem.

Theorem 1.1. Let $C$ be a closed and convex subset of a Hilbert space $H$ and let $T: C \rightarrow C$ be a nonexpansive mapping such that $F(T) \neq \emptyset$. Assume that $\left\{\alpha_{n}\right\}_{n=0}^{\infty}$ is a sequence in $[0,1]$ such that $\alpha_{n} \leq 1-\delta$ for some $\delta \in(0,1]$. Define a sequence $\left\{x_{n}\right\}_{n=0}^{\infty}$ in $C$ by the following algorithm:

$$
\begin{gathered}
x_{0} \in C \text { chosen arbitrarily, } \\
y_{n}=\alpha_{n} x_{n}+\left(1-\alpha_{n}\right) T x_{n}, \\
C_{n}=\left\{z \in C:\left\|y_{n}-z\right\| \leq\left\|x_{n}-z\right\|\right\}, \\
Q_{n}=\left\{z \in C:\left\langle x_{0}-x_{n}, x_{n}-z\right\rangle \geq 0\right\}, \\
x_{n+1}=P_{C_{n} \cap Q_{n}} x_{0} .
\end{gathered}
$$

Then $\left\{x_{n}\right\}$ defined by (1.12) converges strongly to $P_{F(T)} x_{0}$.

Recently, Kim and $\mathrm{Xu}$ [10] extended the result of Nakajo and Takahashi [9] from nonexpansive mappings to asymptotically nonexpansive mappings. They proved the following theorem. 
Theorem 1.2. Let $C$ be a nonempty, bounded, closed, and convex subset of a Hilbert space $H$ and let $T: C \rightarrow C$ be an asymptotically nonexpansive mapping with a sequence $\left\{k_{n}\right\}$ such that $k_{n} \rightarrow 1$ as $n \rightarrow \infty$. Assume that $\left\{\alpha_{n}\right\}_{n=0}^{\infty}$ is a sequence in $[0,1]$ such that $\lim _{\sup } \operatorname{su}_{n \rightarrow \infty} \alpha_{n}<1$. Define a sequence $\left\{x_{n}\right\}$ in $C$ by the following algorithm:

$$
\begin{gathered}
x_{0} \in C \text { chosen arbitrarily, } \\
y_{n}=\alpha_{n} x_{n}+\left(1-\alpha_{n}\right) T^{n} x_{n} \\
C_{n}=\left\{z \in C:\left\|y_{n}-z\right\|^{2} \leq\left\|x_{n}-z\right\|^{2}+\theta_{n}\right\}, \\
Q_{n}=\left\{z \in C:\left\langle x_{0}-x_{n}, x_{n}-z\right\rangle \geq 0\right\}, \\
x_{n+1}=P_{C_{n} \cap Q_{n}} x_{0},
\end{gathered}
$$

where $\theta_{n}=\left(1-\alpha_{n}\right)\left(k_{n}^{2}-1\right)(\text { diam C })^{2} \rightarrow 0$, as $n \rightarrow \infty$. Then $\left\{x_{n}\right\}$ defined by (1.13) converges strongly to $P_{F(T)} x_{0}$.

Since 2003, the strong convergence problems of the CQ method for fixed point iteration processes in a Hilbert space or a Banach space have been studied by many authors; see [9-20].

Let $\left\{T_{i}\right\}_{i=1}^{\infty}$ be an infinitely family of uniformly $L_{i}$-Lipschitzian and generalized asymptotically quasi-nonexpansive mappings and let $F:=\bigcap_{i=1}^{\infty} F\left(T_{i}\right)$. In this paper, motivated by Kim and Xu [10] and Nakajo and Takahashi [9], we introduce two kinds of new algorithms for finding a common fixed point of a countable family of uniformly Lipschitzian and generalized asymptotically quasi-nonexpansive mappings which are modifications of the normal Mann iterative scheme. Our iterative schemes are defined as follows.

Algorithm 1.3. For an initial point $x_{0} \in C$, compute the sequence $\left\{x_{n}\right\}$ by the iterative process:

$$
\begin{gathered}
y_{i, n}=\alpha_{i, n} x_{n}+\left(1-\alpha_{i, n}\right) T_{i}^{n} x_{n} \\
C_{i, n}=\left\{z \in C:\left\|y_{i, n}-z\right\|^{2} \leq\left\|x_{n}-z\right\|^{2}-\alpha_{i, n}\left(1-\alpha_{i, n}\right)\left\|T_{i}^{n} x_{n}-x_{n}\right\|^{2}+\left(1-\alpha_{i, n}\right) \theta_{i, n}\right\}, \\
C_{n}=\bigcap_{i=1}^{\infty} C_{i, n} \\
Q_{0}=C, \\
Q_{n}=\left\{z \in Q_{n-1}:\left\langle z-x_{n}, x_{0}-x_{n}\right\rangle \leq 0\right\}, \quad n \geq 1, \\
x_{n+1}=P_{C_{n} \cap Q_{n}} x_{0}, \quad n \geq 0,
\end{gathered}
$$

where $\theta_{i, n}=\left(k_{i, n}^{2}-1\right) \nabla_{n}^{2}+2 k_{i, n} c_{i, n} \nabla_{n}+c_{i, n^{\prime}}^{2} \nabla_{n}=\sup _{n \in \mathbb{N}}\left\{\left\|x_{n}-z\right\|: z \in F\right\}<\infty$. 
Algorithm 1.4. For an initial point $x_{0} \in C$, compute the sequence $\left\{x_{n}\right\}$ by the iterative process:

$$
\begin{gathered}
C_{i, 0}=C, \\
y_{i, n}=\alpha_{i, n} x_{n}+\left(1-\alpha_{i, n}\right) T_{i}^{n} x_{n} \\
C_{i, n+1}=\left\{z \in C_{i, n}:\left\|y_{i, n}-z\right\|^{2} \leq\left\|x_{n}-z\right\|^{2}-\alpha_{i, n}\left(1-\alpha_{i, n}\right)\left\|T_{i}^{n} x_{n}-x_{n}\right\|^{2}+\left(1-\alpha_{i, n}\right) \theta_{i, n}\right\} \\
C_{n+1}=\bigcap_{i=1}^{\infty} C_{i, n+1}, \\
x_{n+1}=P_{C_{n+1}} x_{0}, \quad n \geq 0,
\end{gathered}
$$

where $\theta_{i, n}=\left(k_{i, n}^{2}-1\right) \nabla_{n}^{2}+2 k_{i, n} c_{i, n} \nabla_{n}+c_{i, n^{\prime}}^{2} \nabla_{n}=\sup _{n \in \mathbb{N}}\left\{\left\|x_{n}-z\right\|: z \in F\right\}<\infty$.

\section{Preliminaries}

In this section, we present some useful lemmas which will be used in our main results.

Lemma 2.1 (see [21]). Let $\left\{a_{n}\right\},\left\{b_{n}\right\}$, and $\left\{c_{n}\right\}$ be three sequences of nonnegative numbers such that $b_{n} \geq 1$ and

$$
a_{n+1} \leq b_{n} a_{n}+c_{n}, \quad \forall n \geq 1,
$$

if $\sum_{n=1}^{\infty} c_{n}<\infty$ and $\sum_{n=1}^{\infty}\left(b_{n}-1\right)<\infty$, then $\lim _{n \rightarrow \infty} a_{n}$ exists.

Lemma 2.2 (see [22]). Let $p>1, r>0$ be two fixed numbers. Then a Banach space $E$ is uniformly convex if and only if there exists a continuous, strictly increasing, and convex function $g:[0, \infty) \rightarrow$ $[0, \infty)$ with $g(0)=0$ such that

$$
\|\lambda x+(1-\lambda) y\|^{p} \leq \lambda\|x\|^{p}+(1-\lambda)\|y\|^{p}-\omega_{p}(\lambda) g(\|x-y\|)
$$

for all $x, y \in B_{r}(0)=\{x \in X:\|x\| \leq r\}$ and $\lambda \in[0,1]$ where $\omega_{p}(\lambda)=\lambda(1-\lambda)^{p}+\lambda^{p}(1-\lambda)$.

Lemma 2.3. Let $C$ be a nonempty subset of a Banach space $E$ and let $T: C \rightarrow C$ be a uniformly L-Lipschitzian mapping. Let $\left\{x_{n}\right\}$ be a sequence in $C$ such that $\lim _{n \rightarrow \infty}\left\|x_{n+1}-x_{n}\right\|=0$ and $\lim _{n \rightarrow \infty}\left\|x_{n}-T^{n} x_{n}\right\|=0$. Then $\lim _{n \rightarrow \infty}\left\|x_{n}-T x_{n}\right\|=0$. 
Proof. Since $T$ is uniformly $L$-Lipschitzian, we have

$$
\begin{aligned}
\left\|x_{n}-T x_{n}\right\| \leq & \left\|x_{n}-x_{n+1}\right\|+\left\|x_{n+1}-T^{n+1} x_{n+1}\right\|+\left\|T^{n+1} x_{n+1}-T^{n+1} x_{n}\right\| \\
& +\left\|T^{n+1} x_{n}-T x_{n}\right\| \\
\leq & \left\|x_{n}-x_{n+1}\right\|+\left\|x_{n+1}-T^{n+1} x_{n+1}\right\|+L\left\|x_{n}-x_{n+1}\right\| \\
& +L\left\|T^{n} x_{n}-x_{n}\right\| .
\end{aligned}
$$

It follows that $\lim _{n \rightarrow \infty}\left\|x_{n}-T x_{n}\right\|=0$.

The following lemmas give some characterizations and useful properties of the metric projection $P_{C}$ in a Hilbert space.

Let $H$ be a real Hilbert space with inner product $\langle\cdot, \cdot\rangle$ and norm $\|\cdot\|$ and let $C$ be a closed and convex subset of $H$. For every point $x \in H$, there exists a unique nearest point in $C$, denoted by $P_{C} x$, such that

$$
\left\|x-P_{C} x\right\| \leq\|x-y\|, \quad \forall y \in C
$$

$P_{C}$ is called the metric projection of $H$ onto $C$. We know that $P_{C}$ is a nonexpansive mapping of $H$ onto $C$.

Lemma 2.4 (see [12]). Let $C$ be a closed and convex subset of a real Hilbert space $H$ and let $P_{C}$ be the metric projection from $H$ onto $C$. Given $x \in H$ and $z \in C$, then $z=P_{C} x$ if and only if the following holds:

$$
\langle x-z, y-z\rangle \leq 0, \quad \forall y \in C
$$

Lemma 2.5 (see [9]). Let $C$ be a nonempty, closed, and convex subset of a real Hilbert space $H$ and let $P_{C}: H \rightarrow C$ be the matric projection from $H$ onto $C$. Then the following inequality holds:

$$
\left\|y-P_{C} x\right\|^{2}+\left\|x-P_{C} x\right\|^{2} \leq\|x-y\|^{2}, \quad \forall x \in H, \forall y \in C .
$$

Lemma 2.6 (see [12]). Let $H$ be a real Hilbert space. Then the following equations hold:

(i) $\|x-y\|^{2}=\|x\|^{2}-\|y\|^{2}-2\langle x-y, y\rangle$, for all $x, y \in H$;

(ii) $\|t x+(1-t) y\|^{2}=t\|x\|^{2}+(1-t)\|y\|^{2}-t(1-t)\|x-y\|^{2}$, for all $t \in[0,1]$ and $x, y \in H$.

Lemma 2.7 (see [10]). Let $C$ be a nonempty, closed, and convex subset of a real Hilbert space $H$. Given $x, y, z \in H$ and also given $a \in \mathbb{R}$, the set

$$
\left\{v \in C:\|y-v\|^{2} \leq\|x-v\|^{2}+\langle z, v\rangle+a\right\}
$$

is convex and closed. 
Lemma 2.8. Let $C$ be a closed and convex subset of a real Hilbert space $H$. Let $T: C \rightarrow C$ be a uniformly L-Lipschitzian and generalized asymptotically quasi-nonexpansive mapping with nonnegative real sequences $\left\{k_{n}\right\},\left\{c_{n}\right\}$ such that $k_{n} \geq 1, \lim _{n \rightarrow \infty} k_{n}=1$ and $\lim _{n \rightarrow \infty} c_{n}=0$. Then $F(T)$ is a closed and convex subset of $C$.

Proof. Since $T$ is continuous, $F(T)$ is closed. Next, we show that $F(T)$ is convex. Let $p_{1}, p_{2} \in$ $F(T)$ and $t \in(0,1)$. Put $p=t p_{1}+(1-t) p_{2}$. By Lemma 2.6, we have

$$
\begin{aligned}
\left\|p-T^{n} p\right\|^{2}= & \left\|t\left(T^{n} p-p_{1}\right)+(1-t)\left(T^{n} p-p_{2}\right)\right\|^{2} \\
= & t\left\|T^{n} p-p_{1}\right\|^{2}+(1-t)\left\|T^{n} p-p_{2}\right\|^{2}-t(1-t)\left\|p_{1}-p_{2}\right\|^{2} \\
\leq & t\left(k_{n}\left\|p-p_{1}\right\|+c_{n}\right)^{2}+(1-t)\left(k_{n}\left\|p-p_{2}\right\|+c_{n}\right)^{2} \\
& -t(1-t)\left\|p_{1}-p_{2}\right\|^{2} \\
= & t(1-t)^{2} k_{n}^{2}\left\|p_{1}-p_{2}\right\|^{2}+(1-t) t^{2} k_{n}^{2}\left\|p_{1}-p_{2}\right\|^{2} \\
& -t(1-t)\left\|p_{1}-p_{2}\right\|^{2}+2 t k_{n} c_{n}\left\|p-p_{1}\right\|+t c_{n}^{2} \\
& +2(1-t) k_{n} c_{n}\left\|p-p_{2}\right\|+(1-t) c_{n}^{2} \\
= & \left((1-t) t\left(k_{n}^{2}-1\right)\right)\left\|p_{1}-p_{2}\right\|^{2}+2 t k_{n} c_{n}\left\|p-p_{1}\right\|+t c_{n}^{2} \\
& +2(1-t) k_{n} c_{n}\left\|p-p_{2}\right\|+(1-t) c_{n}^{2} .
\end{aligned}
$$

This implies that $\lim _{n \rightarrow \infty}\left\|p-T^{n} p\right\|=0$. Since $T$ is continuous, we have $\lim _{n \rightarrow \infty}\left\|T p-T^{n+1} p\right\|=$ 0 , so that $p=T p$. Hence $p \in F(T)$.

\section{Main Results}

First, we prove a weak convergence theorem for a single uniformly Lipschitzian and generalized asymptotically quasi-nonexpansive mapping in a uniformly convex Banach space.

Theorem 3.1. Let E be a uniformly convex Banach space E which satisfies Opial's property. Let $C$ be a nonempty, closed, and convex subset of $E$, and $T: C \rightarrow C$ a uniformly L-Lipschitzian and generalized asymptotically quasi-nonexpansive mapping with nonnegative real sequences $\left\{k_{n}\right\},\left\{c_{n}\right\}$ such that $k_{n} \geq 1, \lim _{n \rightarrow \infty} k_{n}=1$ and $\lim _{n \rightarrow \infty} c_{n}=0$. Assume that $I-T$ is demiclosed at 0 , where $I$ is the identity mapping of $C$ and $\left\{\alpha_{n}\right\}$ is a sequence in $[0,1]$ such that $0<\liminf _{n \rightarrow \infty} \alpha_{n} \leq \limsup _{n \rightarrow \infty} \alpha_{n}<1$ and $\sum_{n=1}^{\infty}\left(k_{n}-1\right)<\infty, \sum_{n=1}^{\infty} c_{n}<\infty$. Let $\left\{x_{n}\right\}$ be the sequence in $C$ generated by the modified Mann iteration process:

$$
x_{n+1}=\alpha_{n} x_{n}+\left(1-\alpha_{n}\right) T^{n} x_{n}, \quad \forall n \in \mathbb{N} .
$$

Then $\left\{x_{n}\right\}$ converges weakly to a fixed point of $F(T)$. 
Proof. Let $p \in F(T)$, we have

$$
\begin{aligned}
\left\|x_{n+1}-p\right\| & \leq \alpha_{n}\left\|x_{n}-p\right\|+\left(1-\alpha_{n}\right)\left\|T^{n} x_{n}-p\right\| \\
& \leq \alpha_{n}\left\|x_{n}-p\right\|+\left(1-\alpha_{n}\right) k_{n}\left\|x_{n}-p\right\|+\left(1-\alpha_{n}\right) c_{n} \\
& \leq\left(1+\left(k_{n}-1\right)\left(1-\alpha_{n}\right)\right)\left\|x_{n}-p\right\|+\left(1-\alpha_{n}\right) c_{n} .
\end{aligned}
$$

Since $\sum_{n=1}^{\infty}\left(k_{n}-1\right)<\infty, \sum_{n=1}^{\infty} c_{n}<\infty$, then by Lemma 2.1 and (3.2), we obtain that

$$
\lim _{n \rightarrow \infty}\left\|x_{n}-p\right\|
$$

exists.

This implies that $\left\{T^{n} x_{n}-p\right\}$ is bounded. Put $r=\max \left\{\sup _{n \in N}\left\|T^{n} x_{n}-p\right\|, \sup _{n \in N} \| x_{n}-\right.$ $p \|\}$. By Lemma 2.2, there is a continuous strictly increasing convex function $g:[0, \infty) \rightarrow$ $[0, \infty)$ with $g(0)=0$ such that

$$
\begin{aligned}
\left\|x_{n+1}-p\right\|^{2}= & \left\|\alpha_{n}\left(x_{n}-p\right)+\left(1-\alpha_{n}\right)\left(T^{n} x_{n}-p\right)\right\|^{2} \\
\leq & \alpha_{n}\left\|x_{n}-p\right\|^{2}+\left(1-\alpha_{n}\right)\left\|T^{n} x_{n}-p\right\|^{2}-\alpha_{n}\left(1-\alpha_{n}\right) g\left(\left\|T^{n} x_{n}-x_{n}\right\|\right) \\
\leq & \alpha_{n}\left\|x_{n}-p\right\|^{2}+\left(1-\alpha_{n}\right) k_{n}^{2}\left\|x_{n}-p\right\|^{2} \\
& +2\left(1-\alpha_{n}\right) k_{n} c_{n}\left\|x_{n}-p\right\| \\
& +\left(1-\alpha_{n}\right) c_{n}^{2}-\alpha_{n}\left(1-\alpha_{n}\right) g\left(\left\|T^{n} x_{n}-x_{n}\right\|\right) .
\end{aligned}
$$

It follows that

$$
\begin{aligned}
\alpha_{n}\left(1-\alpha_{n}\right) g\left(\left\|T^{n} x_{n}-x_{n}\right\|\right) \leq & \left(k_{n}^{2}-\alpha_{n}\left(k_{n}^{2}-1\right)\right)\left\|x_{n}-p\right\|^{2} \\
& -\left\|x_{n+1}-p\right\|^{2} \\
& +2\left(1-\alpha_{n}\right) k_{n} c_{n}\left\|x_{n}-p\right\| \\
& +\left(1-\alpha_{n}\right) c_{n}^{2} .
\end{aligned}
$$

By our assumptions and (3.3), we get $\lim _{n \rightarrow \infty} g\left(\left\|T^{n} x_{n}-x_{n}\right\|\right)=0$. Since $g$ is continuous strictly increasing with $g(0)=0$, we can conclude that $\lim _{n \rightarrow \infty}\left\|T^{n} x_{n}-x_{n}\right\|=0$. Observe that $\| x_{n+1}-$ $x_{n}\left\|\leq \alpha_{n}\right\| T^{n} x_{n}-x_{n} \| \rightarrow 0$. It follows from Lemma 2.3 that $\lim _{n \rightarrow \infty}\left\|x_{n}-T x_{n}\right\|=0$. Since $\left\{x_{n}\right\}$ is bounded, there exists a subsequence $\left\{x_{n_{k}}\right\}$ of $\left\{x_{n}\right\}$ converging weakly to some $q_{1} \in C$. From $\lim _{n \rightarrow \infty}\left\|x_{n}-T x_{n}\right\|=0$ and $I-T$ is demiclosed at 0 , we obtain that $T q_{1}=q_{1}$. That is, $q_{1} \in F(T)$. Next, we show that $\left\{x_{n}\right\}$ converges weakly to $q_{1}$ and take another subsequence $\left\{x_{m_{k}}\right\}$ of $\left\{x_{n}\right\}$ 
converging weakly to some $q_{2} \in C$. Again, as above, we can conclude that $q_{2} \in F(T)$. Finally, we show that $q_{1}=q_{2}$. Assume $q_{1} \neq q_{2}$. Then by Opial's property of $E$, we have

$$
\begin{aligned}
\lim _{n \rightarrow \infty}\left\|x_{n}-q_{1}\right\| & =\lim _{k \rightarrow \infty}\left\|x_{n_{k}}-q_{1}\right\| \\
& <\lim _{k \rightarrow \infty}\left\|x_{n_{k}}-q_{2}\right\| \\
& =\lim _{n \rightarrow \infty}\left\|x_{n}-q_{2}\right\| \\
& =\lim _{k \rightarrow \infty}\left\|x_{m_{k}}-q_{2}\right\| \\
& <\lim _{k \rightarrow \infty}\left\|x_{m_{k}}-q_{1}\right\| \\
& =\lim _{n \rightarrow \infty}\left\|x_{n}-q_{1}\right\|,
\end{aligned}
$$

which is a contradiction. Therefore $q_{1}=q_{2}$. This shows that $\left\{x_{n}\right\}$ converges weakly to $q_{1} \in$ $F(T)$.

Remark 3.2. (1) In [3, Theorem 2], Bruck et al. proved that if $T: C \rightarrow C$ is asymptotically nonexpansive in the weak sense and $T$ is $\tau$-asymptotically regular, then Picard's iterated sequence $\left\{T^{n} x\right\}$ is $\tau$-convergent to a fixed point of $T$. Since every asymptotically nonexpansive in the weak sense is a generalized asymptotically nonexpansive mapping and if its fixed point set is nonempty, then it is a generalized quasiasymptotically nonexpansive mapping. So we can apply Theorem 3.1 with a mapping $T$ which is asymptotically nonexpansive in the weak sense when its fixed point set is nonempty and obtain that the sequence $\left\{x_{n}\right\}$ generated by the modified Mann iteration process

$$
x_{n+1}=\alpha_{n} x_{n}+\left(1-\alpha_{n}\right) T^{n} x_{n}, \quad \forall n \in \mathbb{N}
$$

converges weakly to a fixed point of $T$ without asymptotically regularity condition of $T$.

(2) In [3, Theorem 4], Bruck et al. showed that if $C$ is a bounded convex subset of a uniformly convex Banach space and $C$ is sequentially $\tau$-compact, $T: C \rightarrow C$ is asymptotically nonexpansive in the intermediate sense and $\sum_{i=1}^{\infty} c_{n_{i}}<\infty$ where $c_{n}=\max \left\{0, \sup _{x, y \in C}\left(\| T^{n} x-\right.\right.$ $\left.\left.T^{n} y\|-\| x-y \|\right)\right\}$ for some sequence of nonnegative integers $\left\{n_{i}\right\}$, then the sequence $\left\{x_{i}\right\}$ generated by

$$
x_{i+1}=\alpha_{i} x_{i}+\left(1-\alpha_{i}\right) T^{n_{i}} x_{i}
$$

is $\tau$-convergent to a fixed point of $T$. Note that every asymptotically nonexpansive mapping in the intermediate sense is a generalized asymptotically nonexpansive mapping. Hence, Theorem 3.1 can be applied to the class of asymptotically nonexpansive mappings in the intermediate sense to obtain weak convergence of the sequence $\left\{x_{n}\right\}$ generated by

$$
x_{n+1}=\alpha_{n} x_{n}+\left(1-\alpha_{n}\right) T^{n} x_{n}, \quad \forall n \in \mathbb{N}
$$

without the boundedness and compactness conditions on $C$. 
Note that the modified Mann's iteration in Theorem 3.1 has only weak convergence.

Question 1. How can we modify the modified Mann's iteration in order to obtain strong convergence?

In the following theorem, we introduce a monotone hybrid method with the modified Mann's iteration to obtain a strong convergence theorem for an infinite family of uniformly Lipschitzian and generalized asymptotically quasi-nonexpansive mappings.

Theorem 3.3. Let $C$ be a closed and convex subset of a real Hilbert space H. Let $\left\{T_{i}\right\}_{i=1}^{\infty}$ be an infinitely countable family of uniformly $L_{i}$-Lipschitzian and generalized asymptotically quasinonexpansive mappings of $C$ into itself with nonnegative real sequences $\left\{k_{i, n}\right\},\left\{c_{i, n}\right\}$ such that $k_{i, n} \geq 1, \lim _{n \rightarrow \infty} k_{i, n}=1, \lim _{n \rightarrow \infty} c_{i, n}=0$, for all $i \in N$. Assume that $F:=\bigcap_{i=1}^{\infty} F\left(T_{i}\right) \neq \emptyset$ and the sequence $\alpha_{i, n} \in[0,1)$, for all $i, n \in \mathbb{N}$. Then the sequence $\left\{x_{n}\right\}$ generated by Algorithm 1.3 converges strongly to $P_{F} x_{0}$.

Proof. We split the proof into six steps.

Step 1. Show that $P_{F} x_{0}$ is well defined for every $x_{0} \in C$.

By Lemma 2.8, we obtain that $F\left(T_{i}\right)$ is a closed and convex subset of $C$ for every $i \in \mathbb{N}$. Hence, $F:=\bigcap_{i=1}^{\infty} F\left(T_{i}\right)$ is a nonempty, closed, and convex subset of $C$; consequently, $P_{F} x_{0}$ is well defined for every $x_{0} \in C$.

Step 2. Show that $P_{C_{n} \cap Q_{n}} x_{0}$ is well defined.

From the definition of $C_{n}$ and $Q_{n}$, it is obvious that $Q_{n}$ is closed and convex for each $n \in \mathbb{N}$. It follows from Lemma 2.7 that $C_{i, n}$ is closed and convex for all $i, n \in \mathbb{N}$. This implies that $C_{n}$ is closed and convex for each $n \in \mathbb{N}$. Next, we will show that $F \subset C_{n} \cap Q_{n}$, for all $n \geq 0$. First, we prove that $F \subset C_{i, n}$ for all $n \geq 0$ and $i \in \mathbb{N}$. Since $T_{i}$ is a generalized asymptotically quasi-nonexpansive mapping for all $i \in \mathbb{N}$, we have that for any $p \in F$,

$$
\begin{aligned}
\left\|y_{i, n}-p\right\|^{2}= & \left\|\alpha_{i, n} x_{n}+\left(1-\alpha_{i, n}\right) T_{i}^{n} x_{n}-p\right\|^{2} \\
= & \alpha_{i, n}\left\|x_{n}-p\right\|^{2}+\left(1-\alpha_{i, n}\right)\left\|T_{i}^{n} x_{n}-p\right\|^{2}-\alpha_{i, n}\left(1-\alpha_{i, n}\right)\left\|T_{i}^{n} x_{n}-x_{n}\right\|^{2} \\
\leq & \alpha_{i, n}\left\|x_{n}-p\right\|^{2}+\left(1-\alpha_{i, n}\right)\left(k_{i, n}\left\|x_{n}-p\right\|+c_{i, n}\right)^{2} \\
& -\alpha_{i, n}\left(1-\alpha_{i, n}\right)\left\|T_{i}^{n} x_{n}-x_{n}\right\|^{2} \\
= & \left\|x_{n}-p\right\|^{2}-\alpha_{i, n}\left(1-\alpha_{i, n}\right)\left\|T_{i}^{n} x_{n}-x_{n}\right\|^{2} \\
& +\left(1-\alpha_{i, n}\right)\left(\left(k_{i, n}^{2}-1\right)\left\|x_{n}-p\right\|^{2}+2 k_{i, n} c_{i, n}\left\|x_{n}-p\right\|+c_{i, n}^{2}\right) \\
\leq & \left\|x_{n}-p\right\|^{2}-\alpha_{i, n}\left(1-\alpha_{i, n}\right)\left\|T_{i}^{n} x_{n}-x_{n}\right\|^{2}+\left(1-\alpha_{i, n}\right) \theta_{i, n} .
\end{aligned}
$$

Hence, $p \in C_{i, n}$ for all $n \geq 0$ and $i \in \mathbb{N}$. This proves that $F \subset C_{i, n}$ for all $n \geq 0$ and $i \in \mathbb{N}$. Hence, $F \subset C_{n}$ for all $n \geq 0$. 
As shown in Marino and Xu [12], by induction, we can show that $F \subset Q_{n}$ for all $n \geq 0$. Hence $F \subset C_{n} \cap Q_{n}$, for all $n \geq 0$, and so $P_{C_{n} \cap Q_{n}} x_{0}$ is well defined.

Step 3. Show that $\lim _{n \rightarrow \infty}\left\|x_{n}-x_{0}\right\|$ exists.

From $x_{n}=P_{Q_{n}} x_{0}$ and $x_{n+1} \in Q_{n}$, we have

$$
\left\|x_{n}-x_{0}\right\| \leq\left\|x_{n+1}-x_{0}\right\|, \quad \forall n \geq 0 .
$$

On the other hand, as $F \subset Q_{n}$, we obtain

$$
\left\|x_{n}-x_{0}\right\| \leq\left\|z-x_{0}\right\|, \quad \forall n \geq 0, \forall z \in F .
$$

So we have that the sequence $\left\{x_{n}\right\}$ is bounded and nondecreasing. Therefore $\lim _{n \rightarrow \infty}\left\|x_{n}-x_{0}\right\|$ exists.

Step 4. Show that $x_{n} \rightarrow q$, where $q \in C$.

For $m>n$, by the definition of $Q_{n}$, we see that $Q_{m} \subset Q_{n}$. Noting that $x_{m}=P_{Q_{m}} x_{0}$ and $x_{n}=P_{Q_{n}} x_{0}$, by Lemma 2.5, we conclude that

$$
\left\|x_{m}-x_{n}\right\|^{2} \leq\left\|x_{m}-x_{0}\right\|^{2}-\left\|x_{n}-x_{0}\right\|^{2} .
$$

It follows from Step 3 that $\left\{x_{n}\right\}$ is a Cauchy. So, we can assume that $x_{n} \rightarrow q$ as $n \rightarrow \infty$ for some $q \in C$. In particular, we have that

$$
\lim _{n \rightarrow \infty}\left\|x_{n+1}-x_{n}\right\|=0
$$

Step 5. Show that $\lim _{n \rightarrow \infty}\left\|x_{n}-T_{i} x_{n}\right\|=0$, for all $i \in \mathbb{N}$.

Let $i, n \in \mathbb{N}$. Since $x_{n+1} \in C_{n}$, it follows from (3.10) that

$$
\left\|y_{i, n}-x_{n+1}\right\|^{2} \leq\left\|x_{n}-x_{n+1}\right\|^{2}-\alpha_{i, n}\left(1-\alpha_{i, n}\right)\left\|T_{i}^{n} x_{n}-x_{n}\right\|^{2}+\left(1-\alpha_{i, n}\right) \theta_{i, n} .
$$

Moreover, by Lemma 2.6, we have

$$
\begin{aligned}
\left\|y_{i, n}-x_{n+1}\right\|^{2}= & \left\|\alpha_{i, n} x_{n}+\left(1-\alpha_{i, n}\right) T_{i}^{n} x_{n}-x_{n+1}\right\|^{2} \\
= & \alpha_{i, n}\left\|x_{n}-x_{n+1}\right\|^{2}+\left(1-\alpha_{i, n}\right)\left\|T_{i}^{n} x_{n}-x_{n+1}\right\|^{2} \\
& -\alpha_{i, n}\left(1-\alpha_{i, n}\right)\left\|T_{i}^{n} x_{n}-x_{n}\right\|^{2} .
\end{aligned}
$$


It follows from (3.15) and (3.16) that

$$
\left(1-\alpha_{i, n}\right)\left\|T_{i}^{n} x_{n}-x_{n+1}\right\|^{2} \leq\left(1-\alpha_{i, n}\right)\left\|x_{n}-x_{n+1}\right\|^{2}+\left(1-\alpha_{i, n}\right) \theta_{i, n}
$$

Since $\theta_{i, n} \rightarrow 0$ as $n \rightarrow \infty$ for all $i \in \mathbb{N}$, we have by (3.14) and (3.17) that

$$
\lim _{n \rightarrow \infty}\left\|T_{i}^{n} x_{n}-x_{n+1}\right\|=0
$$

This implies that

$$
\left\|T_{i}^{n} x_{n}-x_{n}\right\| \leq\left\|T_{i}^{n} x_{n}-x_{n+1}\right\|+\left\|x_{n+1}-x_{n}\right\| \longrightarrow 0
$$

for all $i \in \mathbb{N}$. By Lemma 2.3 and (3.14), we get that $\lim _{n \rightarrow \infty}\left\|x_{n}-T_{i} x_{n}\right\|=0$ for all $i \in \mathbb{N}$.

Step 6. Show that $q=P_{F} x_{0}$.

Since $x_{n} \rightarrow q$ and $\lim _{n \rightarrow \infty}\left\|x_{n}-T_{i} x_{n}\right\|=0$ for all $i \in \mathbb{N}$, we have $q=T_{i} q$ for all $i \in \mathbb{N}$. Hence $q \in F$. By Lemma 2.4, we obtain

$$
\left\langle z-x_{n}, x_{0}-x_{n}\right\rangle \leq 0
$$

for all $z \in Q_{n-1} \cap C_{n-1}$. Since $F \subset Q_{n-1} \cap C_{n-1}$, we have

$$
\left\langle z-q, x_{0}-q\right\rangle \leq 0
$$

for all $z \in F$. Again by Lemma 2.4, we obtain that $q=P_{F} x_{0}$. This completes the proof.

Theorem 3.4. Let $C$ be a closed and convex subset of a real Hilbert space $H$. Let $\left\{T_{i}\right\}_{i=1}^{\infty}$ be an infinitely countable family of uniformly $L_{i}$-Lipschitzian and generalized asymptotically quasinonexpansive mappings of $C$ into itself with nonnegative real sequences $\left\{k_{i, n}\right\},\left\{c_{i, n}\right\}$ such that $k_{i, n} \geq 1, \lim _{n \rightarrow \infty} k_{i, n}=1, \lim _{n \rightarrow \infty} c_{i, n}=0$, for all $i \in \mathbb{N}$. Assume that $F:=\bigcap_{i=1}^{\infty} F\left(T_{i}\right) \neq \emptyset$ and the sequence $\left\{\alpha_{i, n}\right\} \subset[0,1)$, for all $i, n \in \mathbb{N}$. Then the sequence $\left\{x_{n}\right\}$ generated by Algorithm 1.4 converges strongly to $P_{F} x_{0}$.

Proof. We divide our proof into four steps.

Step 1. Show that $C_{n}$ is closed and convex and $F \subset C_{n}$ for all $n \geq 1$.

It follows from Lemma 2.7 that $C_{i, n}$ is closed and convex for all $i, n \in \mathbb{N}$. This implies that $C_{n}$ is closed and convex for each $n \in \mathbb{N}$. Next, we will show that $F \subset C_{i, n}$ for all $n \in \mathbb{N}$. For $n=1, F \subset C_{i, 1}=C$. Assume that $F \subset C_{i, n}$ for $n \in \mathbb{N}$. It follows from (3.10) and the definition of $C_{i, n+1}$ that $F \subset C_{i, n+1}$.

Step 2. Show that $\lim _{n \rightarrow \infty}\left\|x_{n}-x_{0}\right\|$ exists.

From $x_{n}=P_{C_{n}} x_{0}, C_{n+1} \subset C_{n}$ and $x_{n+1} \in C_{n}$, for all $n \geq 0$, we have

$$
\left\|x_{n}-x_{0}\right\| \leq\left\|x_{n+1}-x_{0}\right\|, \quad \forall n \geq 0 .
$$


On the other hand, as $F \subset C_{n}$, we obtain

$$
\left\|x_{n}-x_{0}\right\| \leq\left\|z-x_{0}\right\|, \quad \forall n \geq 0, \forall z \in F
$$

So we have that the sequence $\left\{x_{n}\right\}$ is bounded and nondecreasing. Therefore $\lim _{n \rightarrow \infty}\left\|x_{n}-x_{0}\right\|$ exists.

Step 3. Show that $x_{n} \rightarrow q$, where $q \in C$.

For $m>n$, by the definition of $C_{n}$, we see that $x_{m}=P_{C_{m}} x_{0} \in C_{m} \subset C_{n}$. By Lemma 2.5, we obtain that

$$
\left\|x_{m}-x_{n}\right\|^{2} \leq\left\|x_{m}-x_{0}\right\|^{2}-\left\|x_{n}-x_{0}\right\|^{2} .
$$

From Step 2, we obtain that $\left\{x_{n}\right\}$ is Cauchy. Hence $x_{n} \rightarrow q$ as $n \rightarrow \infty$ for some $q \in C$ and $\lim _{n \rightarrow \infty}\left\|x_{n+1}-x_{n}\right\|=0$. By using the same proof as in Step 5 of Theorem 3.3, we can show that $\lim _{n \rightarrow \infty}\left\|x_{n}-T_{i} x_{n}\right\|=0$, for all $i \in \mathbb{N}$.

Step 4. Show that $q=P_{F} x_{0}$.

Since $x_{n} \rightarrow q$ and $\lim _{n \rightarrow \infty}\left\|x_{n}-T_{i} x_{n}\right\|=0$, for all $i \in \mathbb{N}$, we have $q=T_{i} q$, for all $i \in \mathbb{N}$. Hence $q \in F$. Since $x_{n}=P_{C_{n}} x_{0}$, by Lemma 2.4 , we have

$$
\left\langle z-x_{n}, x_{0}-x_{n}\right\rangle \leq 0
$$

for all $z \in C_{n}$, and hence,

$$
\left\langle z-q, x_{0}-q\right\rangle \leq 0
$$

for all $z \in F$. This shows that $q=P_{F} x_{0}$, which completes the proof.

Since a generalized asymptotically quasi-nonexpansive mapping is to unify various classes of mappings associated with the class of generalized asymptotically nonexpansive mapping, we have the following.

Corollary 3.5. Let $C$ be a closed and convex subset of a real Hilbert space $H$. Let $\left\{T_{i}\right\}_{i=1}^{\infty}$ be an infinitely countable family of uniformly $L_{i}$-Lipschitzian and generalized asymptotically nonexpansive mappings of $C$ into itself with nonnegative real sequences $\left\{k_{i, n}\right\},\left\{c_{i, n}\right\}$ such that $k_{i, n} \geq 1$, 
$\lim _{n \rightarrow \infty} k_{i, n}=1, \lim _{n \rightarrow \infty} c_{i, n}=0$, for all $i \in N$. Assume that $F:=\bigcap_{i=1}^{\infty} F\left(T_{i}\right) \neq \emptyset$ and the sequence $\left\{\alpha_{i, n}\right\} \subset[0,1)$, for all $i, n \in \mathbb{N}$. Let a sequence $\left\{x_{n}\right\}$ be generated by the following manner:

$$
\begin{gathered}
x_{0} \in C \text { chosen arbitrarily, } \\
y_{i, n}=\alpha_{i, n} x_{n}+\left(1-\alpha_{i, n}\right) T_{i}^{n} x_{n} \\
C_{i, n}=\left\{z \in C:\left\|y_{i, n}-z\right\|^{2} \leq\left\|x_{n}-z\right\|^{2}-\alpha_{i, n}\left(1-\alpha_{i, n}\right)\left\|T_{i}^{n} x_{n}-x_{n}\right\|^{2}+\left(1-\alpha_{i, n}\right) \theta_{i, n}\right\}, \\
C_{n}=\bigcap_{i=1}^{\infty} C_{i, n} \\
Q_{0}=C, \\
Q_{n}=\left\{z \in Q_{n-1}:\left\langle z-x_{n}, x_{0}-x_{n}\right\rangle \leq 0\right\}, \quad n \geq 1, \\
x_{n+1}=P_{C_{n} \cap Q_{n}} x_{0}, \quad n \geq 0,
\end{gathered}
$$

where $\theta_{i, n}=\left(k_{i, n}^{2}-1\right) \nabla_{n}^{2}+2 k_{i, n} c_{i, n} \nabla_{n}+c_{i, n^{\prime}}^{2} \nabla_{n}=\sup _{n \in \mathbb{N}}\left\{\left\|x_{n}-z\right\|: z \in F\right\}<\infty$. Then the sequence $\left\{x_{n}\right\}$ converges strongly to $P_{F} x_{0}$.

Corollary 3.6. Let $C$ be a closed and convex subset of a real Hilbert space $H$. Let $\left\{T_{i}\right\}_{i=1}^{\infty}$ be an infinitely countable family of uniformly $L_{i}$-Lipschitzian and generalized asymptotically nonexpansive mappings of $C$ into itself with nonnegative real sequences $\left\{k_{i, n}\right\},\left\{c_{i, n}\right\}$ such that $k_{i, n} \geq 1$, $\lim _{n \rightarrow \infty} k_{i, n}=1, \lim _{n \rightarrow \infty} c_{i, n}=0$, for all $i \in N$. Assume that $F:=\bigcap_{i=1}^{\infty} F\left(T_{i}\right) \neq \emptyset$ and the sequence $\left\{\alpha_{i, n}\right\} \subset[0,1)$, for all $i, n \in \mathbb{N}$. Let a sequence $\left\{x_{n}\right\}$ be generated by the following manner:

$$
\begin{gathered}
x_{0} \in C \quad \text { chosen arbitrarily, } \\
C_{i, 0}=C \\
y_{i, n}=\alpha_{i, n} x_{n}+\left(1-\alpha_{i, n}\right) T_{i}^{n} x_{n} \\
C_{i, n+1}=\left\{z \in C_{i, n}:\left\|y_{i, n}-z\right\|^{2} \leq\left\|x_{n}-z\right\|^{2}-\alpha_{i, n}\left(1-\alpha_{i, n}\right)\left\|T_{i}^{n} x_{n}-x_{n}\right\|^{2}+\left(1-\alpha_{i, n}\right) \theta_{i, n}\right\} \\
C_{n+1}=\bigcap_{i=1}^{\infty} C_{i, n+1}, \\
x_{n+1}=P_{C_{n+1}} x_{0}, \quad n \geq 0,
\end{gathered}
$$

where $\theta_{i, n}=\left(k_{i, n}^{2}-1\right) \nabla_{n}^{2}+2 k_{i, n} c_{i, n} \nabla_{n}+c_{i, n^{\prime}}^{2} \nabla_{n}=\sup _{n \in \mathbb{N}}\left\{\left\|x_{n}-z\right\|: z \in F\right\}<\infty$. Then the sequence $\left\{x_{n}\right\}$ converges strongly to $P_{F} x_{0}$.

Remark 3.7. (i) Corollaries 3.5 and 3.6 improve and extend the main result in [10].

(ii) If we take $T_{i}=T, k_{i, n}=1$ and $c_{i, n}=0$ for all $i, n \in \mathbb{N}$ where $T$ is a nonexpansive mapping, then Corollary 3.5 reduces to [9, Theorem 3.4]. 


\section{Acknowledgments}

The authors would like to thank the referees for valuable suggestions on the manuscript. The authors were supported by the Center of Excellence in Mathematics, the Thailand Research Fund, the Commission on Higher Education, and the Graduate School of Chiang Mai University for the financial support.

\section{References}

[1] N. Shahzad and H. Zegeye, "Strong convergence of an implicit iteration process for a finite family of generalized asymptotically quasi-nonexpansive maps," Applied Mathematics and Computation, vol. 189, no. 2, pp. 1058-1065, 2007.

[2] W. A. Kirk, "Fixed point theorems for non-Lipschitzian mappings of asymptotically nonexpansive type," Israel Journal of Mathematics, vol. 17, pp. 339-346, 1974.

[3] R. Bruck, T. Kuczumow, and S. Reich, "Convergence of iterates of asymptotically nonexpansive mappings in Banach spaces with the uniform Opial property," Colloquium Mathematicum, vol. 65, no. 2, pp. 169-179, 1993.

[4] Z. Opial, "Weak convergence of the sequence of successive approximations for nonexpansive mappings," Bulletin of the American Mathematical Society, vol. 73, pp. 591-597, 1967.

[5] W. R. Mann, "Mean value methods in iteration," Proceedings of the American Mathematical Society, vol. 4, pp. 506-510, 1953.

[6] H. H. Bauschke, E. Matoušková, and S. Reich, "Projection and proximal point methods: convergence results and counterexamples," Nonlinear Analysis: Theory, Methods E Applications, vol. 56, no. 5, pp. 715-738, 2004.

[7] A. Genel and J. Lindenstrauss, "An example concerning fixed points," Israel Journal of Mathematics, vol. 22, no. 1, pp. 81-86, 1975.

[8] S. Reich, "Weak convergence theorems for nonexpansive mappings in Banach spaces," Journal of Mathematical Analysis and Applications, vol. 67, no. 2, pp. 274-276, 1979.

[9] K. Nakajo and W. Takahashi, "Strong convergence theorems for nonexpansive mappings and nonexpansive semigroups," Journal of Mathematical Analysis and Applications, vol. 279, no. 2, pp. 372 $379,2003$.

[10] T.-H. Kim and H.-K. Xu, "Strong convergence of modified Mann iterations for asymptotically nonexpansive mappings and semigroups," Nonlinear Analysis: Theory, Methods \& Applications, vol. 64, no. 5, pp. 1140-1152, 2006.

[11] P. Cholamjiak, "A hybrid iterative scheme for equilibrium problems, variational inequality problems, and fixed point problems in Banach spaces," Fixed Point Theory and Applications, vol. 2009, Article ID 719360, 18 pages, 2009.

[12] G. Marino and H.-K. Xu, "Weak and strong convergence theorems for strict pseudo-contractions in Hilbert spaces," Journal of Mathematical Analysis and Applications, vol. 329, no. 1, pp. 336-346, 2007.

[13] C. Martinez-Yanes and H.-K. Xu, "Strong convergence of the CQ method for fixed point iteration processes," Nonlinear Analysis: Theory, Methods E Applications, vol. 64, no. 11, pp. 2400-2411, 2006.

[14] W. Nilsrakoo and S. Saejung, "Weak and strong convergence theorems for countable Lipschitzian mappings and its applications," Nonlinear Analysis: Theory, Methods \& Applications, vol. 69, no. 8, pp. 2695-2708, 2008.

[15] W. Nilsrakoo and S. Saejung, "Strong convergence theorems for a countable family of quasiLipschitzian mappings and its applications," Journal of Mathematical Analysis and Applications, vol. 356, no. 1, pp. 154-167, 2009.

[16] D. R. Sahu, H.-K. Xu, and J.-C. Yao, "Asymptotically strict pseudocontractive mappings in the intermediate sense," Nonlinear Analysis: Theory, Methods E Applications, vol. 70, no. 10, pp. 3502-3511, 2009.

[17] A. Tada and W. Takahashi, "Weak and strong convergence theorems for a nonexpansive mapping and an equilibrium problem," Journal of Optimization Theory and Applications, vol. 133, no. 3, pp. 359-370, 2007.

[18] W. Takahashi, Y. Takeuchi, and R. Kubota, "Strong convergence theorems by hybrid methods for families of nonexpansive mappings in Hilbert spaces," Journal of Mathematical Analysis and Applications, vol. 341, no. 1, pp. 276-286, 2008. 
[19] H. Zhou, "Strong convergence theorems for a family of Lipschitz quasi-pseudo-contractions in Hilbert spaces," Nonlinear Analysis: Theory, Methods E Applications, vol. 71, no. 1-2, pp. 120-125, 2009.

[20] H. Zhou and Y. Su, "Strong convergence theorems for a family of quasi-asymptotic pseudocontractions in Hilbert spaces," Nonlinear Analysis: Theory, Methods E Applications, vol. 70, no. 11, pp. 4047-4052, 2009.

[21] M. O. Osilike and S. C. Aniagbosor, "Weak and strong convergence theorems for fixed points of asymptotically nonexpansive mappings," Mathematical and Computer Modelling, vol. 32, no. 10, pp. 1181-1191, 2000.

[22] H. K. Xu, "Inequality in Banach spacees with applications," Nonlinear Analysis: Theory, Methods $\mathcal{E}$ Applications, vol. 16, pp. 1127-1138, 1991. 


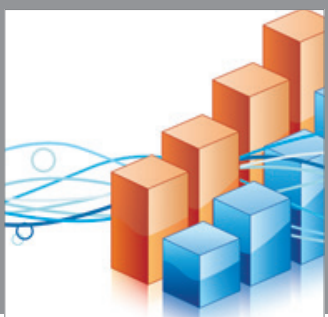

Advances in

Operations Research

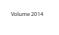

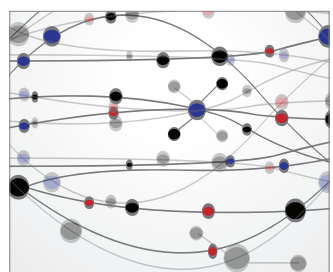

\section{The Scientific} World Journal
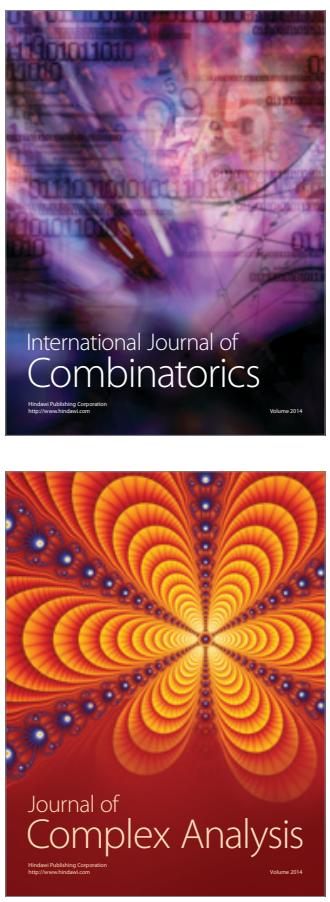

International Journal of

Mathematics and

Mathematical

Sciences
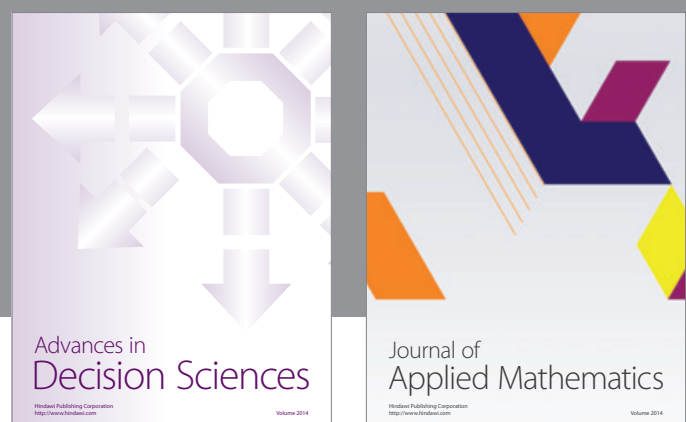

Journal of

Applied Mathematics
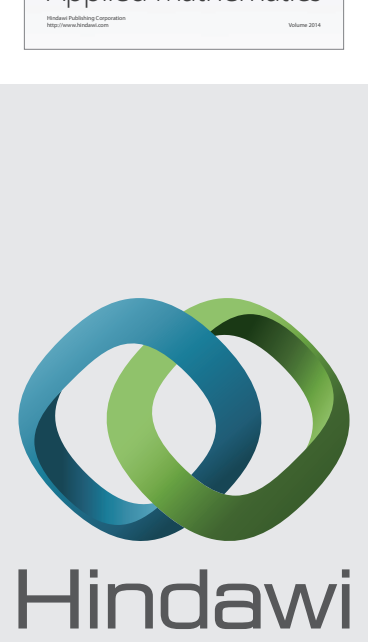

Submit your manuscripts at http://www.hindawi.com
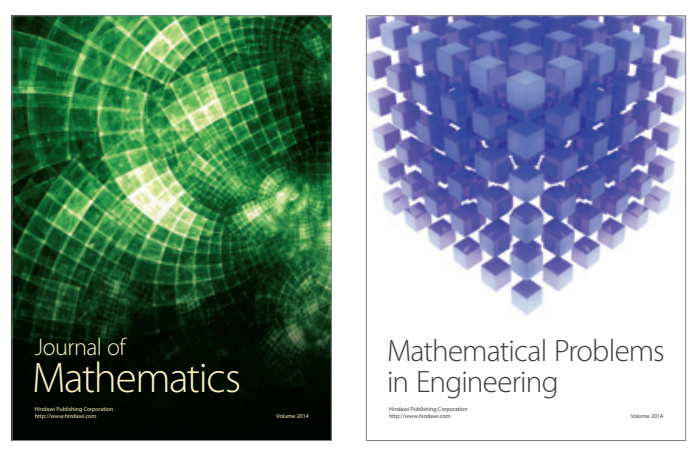

Mathematical Problems in Engineering
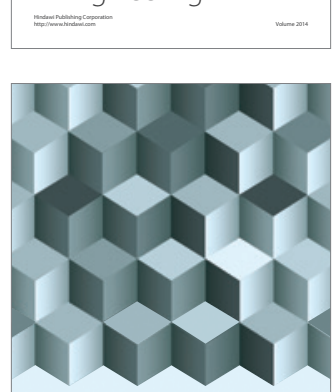

Journal of

Function Spaces
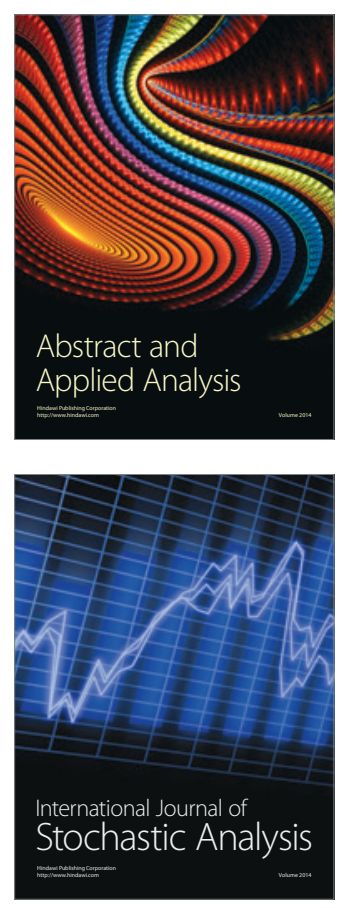

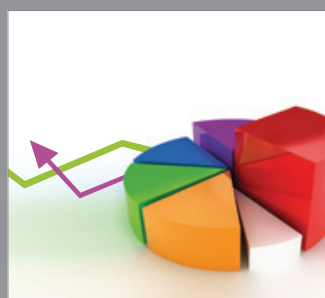

ournal of

Probability and Statistics

Promensencen
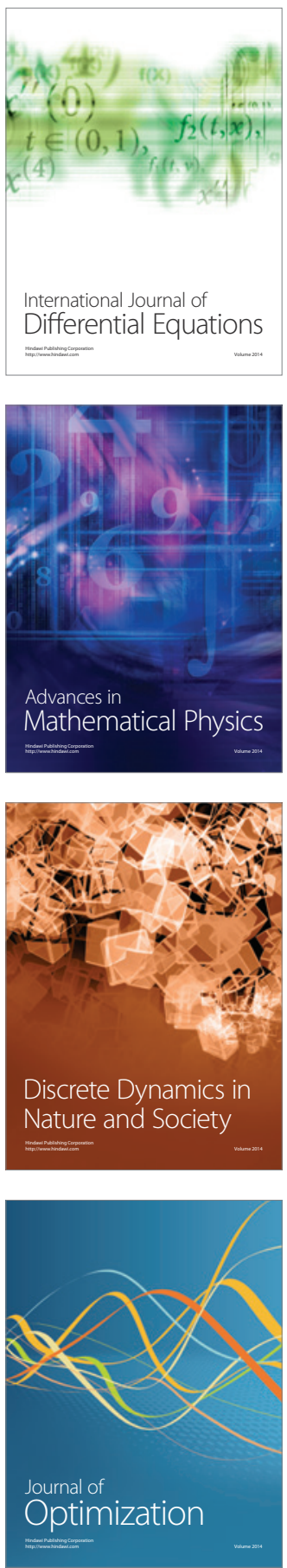